\title{
Measurement of Technical Efficiency of Wet Season Rice Production in Northern Thailand: An Application of DEA Malmquist Index
}

\author{
Sathinee Jongdoen ${ }^{1}$, Wongchai Anupong ${ }^{2}$ and Ke Chung Peng ${ }^{3 *}$ \\ ${ }^{1}$ Department of Tropical Agriculture and International Cooperation, National Pingtung University of Science and Technology, Taiwan \\ ${ }^{2}$ Department of Agricultural Economy and Development, Chiang Mai University, Thailand \\ ${ }^{3}$ Department of Agribusiness Management, National Pingtung University of Science and Technology, Taiwan
}

*Corresponding author: Ke Chung Peng, Department of Agribusiness Management, National Pingtung University of Science and Technology, Taiwan.

To Cite This Article: Ke Chung Peng, Measurement of Technical Efficiency of Wet Season Rice Production in Northern Thailand: An Application of DEA Malmquist Index. Am J Biomed Sci \& Res. 2020 - 7(1). AJBSR.MS.ID.001104. DOI: 10.34297/AJBSR.2020.07.001104.

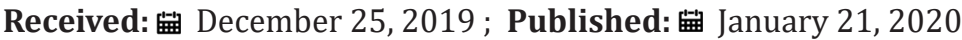

\begin{abstract}
All Thai farmers grow rice as the main crop. Rice production in Thailand plays an important role as an important economic crop. In this paper, to measure the technical efficiency of wet season rice production. The objectives were to analyze the efficiency by using an application of data envelopment analysis and used a panel data by Malmquist Index to identify the trend in wet season rice productivity's change in the crop year $2009 / 2010$ - 2018/2019. The study areas located were in the seventeen provinces in the north of Thailand. The empirical results showed that the average Technical Efficiency (TE) score was 0.892 , the highest TE score was 0.920 and the lowest TE score was 0.860 respectively. Phetchabun province provided the best efficiency. Contrary, Tak province where had the worst efficiency among all the producing provinces of wet season rice.

Besides, the TE score was not close to 1.000 that it meant a province where was the lowest mean technical efficiency score of wet season rice production. It should be used the resources available to generate a set of outputs. In term of the Total Factor Productivity (TFP) change, an average score of TFP performed a high efficiency (1.003) during the ten years. The scores with greater than 1.000 in eleven which implied an improvement in the efficiency as well as technology. On the other hand, the scores with less than 1.000 was found in six provinces which implied a need to improve performance and technology. Therefore, we concluded that the wet season rice production in Northern Thailand achieved the efficiency improvement, the technical progress and the productivity growth between 2009-2019. Moreover, this study can provide important and useful information for farmers, producers, researchers, policy makers, and government agencies to set the plans for using technology to improve efficiency.
\end{abstract}

Keywords: Data Envelopment Analysis (DEA); Malmquist Productivity Index (MPI); Northern; Wet season rice; Technical Efficiency (TE); Thailand; Total Factor Productivity (TFP) change

\section{Introduction}

Thailand is an agricultural country. Half of Thailand's cultivated land is dedicated to rice growing. All Thai farmers, especially in the rural areas, grow rice as the main crop. Rice which plays a significant role as an important economic crop, is also one of major crops in Thailand and it will remain so as long as it continues to be the major export crop and the staple food. Rice production is an important crop in the Thai economy for two main reasons such as [1] for household's consumption and [2] for exporting product to a foreign country. For a long time, Thailand was the world's largest rice exporter. In 2018/2019, Thailand was the world's second-larg est exporter with about 10.3 million metric tons of rice after India which had the highest export volume of rice worldwide, at 12.5 million metric tons as of 2018/2019.

In addition, rice production plays an important role in Thailand's economy and society. The rice production is a source of income and employment both in production and in export manufacturing, particularly from 4 regions of Thailand in the Central, Northeast, North, and South. Each region has different rice-growing environments. Thailand has two annual rice-growing periods, the wet-season and the dry-season. Rice lands can be classified as ir- 
rigated, rainfed lowland, deep water, and upland ecosystems. More than 80 percent of the rice growing area, including the North of Thailand, is under rainfed conditions where rice is usually grown only once a year in the wet season, where the monsoon rain is the single source of water supply for rice cultivation. Less than 20 percent of the area is under irrigated conditions where rice can be grown not only in the wet season but also in the dry season because irrigation water supply is available [3]. The wet- season rice harvest is the larger of two annual crops, normally accounting for roughly 70 percent of total annual production. Wet-season rice acreage has averaged about 8.8 million hectares since 2007.

Wet-season rice is heavily dependent on monsoonal weather systems, with 70 percent of the crop being totally rainfed [4]. The general policy for rice production in Thailand is to produce rice for domestic consumption and a little for exporting to earn foreign exchange. Major production comes from the wet season rice crop with the supplement of the dry season crop. However, Thailand is the main rice-exporting country in the world. On the other hand, rice farmers in Northern Thailand is facing possible the worst drought in 40 years, with crops withering and tap water on the verge of drying up in some areas [5]. The fact has showed and indicated, low productivity and low technical efficiency of rice production. In an Attempt to resolve this problem, the Thai government has promoted the use of inputs in rice production [6].

On the policy, Thai Government intends to improve productivity and farm income. Moreover, improvement and development of irrigation systems for both regions and communities, investment in agricultural $\mathrm{R} \& \mathrm{D}$, improving land productivity and tenure system, providing agricultural credit at a reasonable interest rate, improvement in logistics and storage facilities, and enhance domestic and export market structure [7]. In the past, the country has issued the rice-related policies, such as the rice pledging scheme, the rice price insurance scheme, etc. These schemes have been implemented throughout the country. Some succeed and some failed [8]. Moreover, the one of majority expenses for rice production includes irrigation system. Meanwhile, the season of rice production in Northern Thailand is to be decided by area, irrigation and non-irrigation system that it cannot be predicted.

Therefore, the study aimed to assess (i) technical efficiency by using an application of Data Envelopment Analysis (DEA), and (ii) trend in wet season rice productivity's change over a ten-year period in the crop year 2008/2009 - 2018/2019 by using Malmquist Index of wet season rice production in 17 provinces where located in the north of Thailand that can be pursued and achieved the efficiency by technological change rather than investment driven growth.

\section{Methods}

\section{Data Envelopment Analysis (DEA)}

The empirical part of this study is based on Data Envelopment Analysis (DEA) to estimate changes in Technical Efficiency
(TE), Scale Efficiency (SE), and Total Factor Productivity (TFP) in in Northern Thailand of Rice Production. The DEA concept is a non-parametric method to estimating efficiency that has been developed by [9]. The score is ranked from inefficiency score of 0.000 to efficiency score of 1.000. This technique is a useful research method not only to measure the efficiency of DMUs, but also to evaluate their relative efficiency. A cross-sectional data, panel data, and time-series data can be evaluated by this approach as well. DEA can be either used in output oriented form or input oriented form depending on the purpose of researcher. The input oriented DEA model seeks the maximum possible proportional decrease in input usage with a given output levels. Meanwhile, the output oriented DEA model seeks the maximum possible proportional increase in output with a given set of inputs. In this study, to evaluate the technical efficiency by adopting input-oriented DEA model. The input oriented DEA model can be measured by assuming a constant return to scale in this study mentioned as follows in equation 1 [10].

$$
\begin{gathered}
\stackrel{M I n}{\theta i, \lambda} \theta \\
-y+Y \lambda \geq 0
\end{gathered}
$$

Subject to $\quad \theta^{X i}-X \lambda \geq 0$

$$
\lambda \geq 0 \text { (1) }
$$

\section{Malmquist Total Factor Productivity Index (MPI)}

The Malmquist index was firstly introduced in literature of productivity by [11] that based on the distance function, as a quantity index for use in the analysis of consumption of inputs. [12] combined ideas on the measurement of efficiency from [13] and the measurement of productivity from [14] to construct a Malmquist productivity index directly from input and output data using DEA. This DEA based Malmquist TFP index has proven itself to be a good tool for measuring the productivity change of DMUs. The DEA by Malmquist Index breaks down the productivity change into two components. The first component measures the technical change and the second component measures the technological change. The two component indices can effectively identify the causes of the productivity change. The Malmquist index can be written as shown in equa ᄀtion 2 [15].

$$
\begin{aligned}
& \left(D t t ( x t + 1 , y t + 1 ) \left(D t t(x t, y t) \frac{1}{2} D t t(x t+1, y t+1)\right.\right. \\
& (D t t+1(x t+1, y t+1)(D t t+1(x t, y t) \times D t t(x t, y t)
\end{aligned}
$$

A change value greater than one indicates a positive shift or technical progress, less than one indicate negative shift or technical regress, and equal one indicates no shift in productivity change. After the calculation, $\mathrm{M}$ can take three different values. $\mathrm{M}>1$ indicates the productivity growth; $\mathrm{M}<1$ indicates productivity decline; $\mathrm{M}=$ 
1 means no change in productivity from period t to $t+1$. EC $>1$ denotes the increase of wet season rice production efficiency from the time period t to the time period $t+1 ; E C<1$ denotes the decrease of wet season rice production efficiency; $\mathrm{EC}=1$ means the wet season rice production efficiency remains stable during the period $t$ to the time period $t+1$. $T C>1$ shows there is an advance in technology; $\mathrm{TC}<1$ shows a deteriorating technology; $\mathrm{TC}=1$ means that there is unchanged technology.

\section{Data}

In this study, to estimate the DEA scores and Malmquist TFP indexes of efficiency, a panel data that has been taken from [16] of wet season rice production in the crop year 2009/2010-2018/2019 on seventeen provinces where located in the North of Thailand was used. The North region covers the provinces of Chiang Rai, Phayao, Lampang, Lamphun, Chiang Mai, Mae Hong Son, Tak, Kamphaeng Phet, Sukhothai, Phrae, Nan, Uttaradit, Phitsanulok, Pichit, Nakhon
Sawan, Uthai Thani, and Phetchabun. We used five variables for the DEA. Fours inputs (planted area, irrigated area, seed and amount of fertilizer) and one output (wet season rice production) are used in the analysis. Then, technical efficiency and total factor productivity growth indices are obtained using the computer program [17] DEAP 2.1.

\section{Results}

The Technical Efficiency (TE) is presented in Table 1 of wet season rice production in 17 provinces where located in Northern Thailand. The average Technical Efficiency (TE) score in each year during the period from 2009 to 2019 was $0.888,0.901,0.863$, $0.920,0.917,0.914,0.864,0.899,0.860$, and 0.883 , respectively. Average TE scores are relatively moderate, thus, it is necessary to improve the operational efficiency of wet season rice production in Thailand.

Table 1: Technical Efficiency Scores of Wet Season Rice Production in Northern Thailand from 2009 to 2019.

\begin{tabular}{|c|c|c|c|c|c|c|c|c|c|c|c|}
\hline Province & $\begin{array}{c}2009 / \\
2010 \\
\end{array}$ & $\begin{array}{c}2010 / \\
2011 \\
\end{array}$ & $\begin{array}{c}2011 / \\
2012\end{array}$ & $\begin{array}{c}2012 / \\
2013\end{array}$ & $\begin{array}{c}2013 / \\
2014\end{array}$ & $\begin{array}{r}2014 / \\
2015\end{array}$ & $\begin{array}{c}2015 / \\
2016\end{array}$ & $\begin{array}{c}2016 / \\
2017\end{array}$ & $\begin{array}{r}2017 / \\
2018\end{array}$ & $\begin{array}{r}2018 / \\
2019\end{array}$ & Mean \\
\hline Chiang Rai & 0.931 & 0.935 & 0.936 & 0.996 & 0.963 & 0.953 & 0.908 & 0.919 & 0.864 & 0.905 & 0.931 \\
\hline Phayao & 0.9 & 0.927 & 0.993 & 0.9 & 0.915 & 0.91 & 0.79 & 0.76 & 0.812 & 0.857 & 0.876 \\
\hline Lampang & 0.865 & 0.902 & 0.878 & 0.854 & 0.856 & 0.859 & 0.809 & 0.848 & 0.826 & 0.832 & 0.853 \\
\hline Lamphun & 0.924 & 0.958 & 0.894 & 0.915 & 0.926 & 0.992 & 0.973 & 0.994 & 0.965 & 0.969 & 0.951 \\
\hline Chiang Mai & 0.978 & 1 & 0.986 & 1 & 1 & 1 & 1 & 1 & 0.963 & 0.938 & 0.987 \\
\hline Mae Hong Son & 0.753 & 0.858 & 0.769 & 0.737 & 0.669 & 0.677 & 0.652 & 0.683 & 0.643 & 0.667 & 0.711 \\
\hline Tak & 0.729 & 0.762 & 0.654 & 0.702 & 0.704 & 0.697 & 0.671 & 0.681 & 0.663 & 0.67 & 0.693 \\
\hline KamphaengPhet & 0.866 & 0.886 & 0.891 & 0.968 & 0.965 & 0.946 & 0.939 & 0.985 & 0.894 & 0.936 & 0.928 \\
\hline Sukhothai & 0.835 & 0.864 & 0.865 & 0.91 & 0.907 & 0.906 & 0.725 & 0.916 & 0.761 & 0.818 & 0.851 \\
\hline Phrae & 0.944 & 0.966 & 0.999 & 0.957 & 0.964 & 0.881 & 0.886 & 0.908 & 0.882 & 0.902 & 0.929 \\
\hline Nan & 0.857 & 0.905 & 0.771 & 0.817 & 0.818 & 0.844 & 0.828 & 0.849 & 0.809 & 0.808 & 0.831 \\
\hline Uttaradit & 1 & 1 & 1 & 1 & 1 & 1 & 0.758 & 0.975 & 0.927 & 0.871 & 0.953 \\
\hline Phitsanulok & 0.878 & 0.899 & 0.702 & 0.983 & 0.966 & 0.94 & 0.872 & 0.945 & 0.854 & 0.89 & 0.893 \\
\hline Phichit & 0.858 & 0.882 & 0.724 & 0.979 & 0.976 & 0.954 & 0.917 & 0.973 & 0.885 & 0.966 & 0.911 \\
\hline Nakhon Sawan & 0.907 & 0.807 & 0.656 & 0.922 & 0.953 & 0.979 & 0.964 & 0.848 & 0.865 & 0.987 & 0.889 \\
\hline Uthai Thani & 0.876 & 0.768 & 0.951 & 1 & 1 & 1 & 1 & 1 & 1 & 1 & 0.96 \\
\hline Phetc habun & 1 & 1 & 1 & 1 & 1 & 1 & 1 & 1 & 1 & 1 & 1 \\
\hline Mean & 0.888 & 0.901 & 0.863 & 0.92 & 0.917 & 0.914 & 0.864 & 0.899 & 0.86 & 0.883 & 0.891 \\
\hline
\end{tabular}

The findings from this study showed that the average TE of firm during the period from 2009 to 2019 in Phetchabun province was found to be fully efficient with the average TE score of 1.000 followed by 5 provinces where have the high TE score; Chiang Mai, Uthai Thani, Uttaradit, Lamphun, and Chiang Rai with the average TE score of $0.987,0.960,0.953,0.951$, and 0.931 , respectively. The lowest TE score was 0.693 . Tak province revealed the least efficiency's score. Besides, the average TE score of wet season rice was 0.891 in the crop year 2009 to 2019 which means that it could be achieved $89.1 \%$ by technical efficiency and could be extended the efficient score $11.9 \%$ by decreasing of each input. The empirical results suggested that it could be improved the production for increasing the efficiency performance of wet season rice production in Northern Thailand (Table 1).

In table 2, it showed the results in the productivity trend of the wet season rice production during 2009-2019 by using the Malmquist Productivity Index (MPI). The Average of Efficiency Change (EC), Technological Change (TC), and Total Factor Productivity (TFP) change of wet season rice producing provinces in Northern Thailand were $0.997,1.005$ and 1.003, respectively. The findings indicated that, the TFP of wet season rice production in $\neg$ creased. Besides, for the decomposition effects of the MPI, wet season rice 
production has shown the technical progress and efficiency improve $\neg$ ments when the years 2010 and 2019 are compared, except during of 2009-2010, 2011-2012, 2013-2014, 2014-2015, 2015-
2016 and 2017-2018, which have decreased in the production efficiency and techno $\neg$ logical progress (Table 2).

\begin{tabular}{|c|c|c|c|c|}
\hline \multicolumn{2}{|c|}{ Table 2: Malmquist productivity index (MPI) summary of annual means. } \\
\hline Year & Efficiency Change & Technological Change & Total Factor Productivity Change & Estimates of the Productivity Trend \\
\hline $2009-2010$ & 0.984 & 0.991 & 0.975 & decreasing \\
\hline $2010-2011$ & 1.015 & 1.001 & 1.015 & increasing \\
\hline $2011-2012$ & 0.95 & 0.995 & 0.946 & decreasing \\
\hline $2012-2013$ & 1.072 & 1.068 & 1.144 & increasing \\
\hline $2013-2014$ & 0.995 & 1.002 & 0.997 & decreasing \\
\hline $2014-2015$ & 0.997 & 0.972 & 0.969 & decreasing \\
\hline $2015-2016$ & 0.943 & 0.986 & 0.93 & increasing \\
\hline $2016-2017$ & 1.042 & 1.003 & 1.045 & decreasing \\
\hline $2017-2018$ & 0.956 & 1.04 & 0.995 & increasing \\
\hline $2018-2019$ & 1.028 & 0.999 & 1.027 & increasing \\
\hline Mean & 0.997 & 1.005 & 1.003 & \\
\hline
\end{tabular}

An analysis of changing in efficiency showed that in the wet season rice productivity increased by firm (province) from 2009 to 2019 in Table 3. Through the MPI decomposing, it is possible to determine the sources of the productivity growth. An upward trend was found for the TFP with greater than $1(>1)$ in Chiang Rai, Phayao, Lamphun, Chiang Mai, Kamphaeng Phet, Phrae, Phitsanulok, Pichit, Nakhon Sawan, Uthai Thani, and Phetchabun provinces, which implied an improvement in the efficiency as well as technology. On the other hand, a downward trend with less than 1 was found in Lampang, Mae Hong Son, Tak, Sukhothai, Nan, and Uttaradit provinces, which implied a need to improve performance and technology. In ad $\neg$ dition, the analysis of the MPI showed the efficiency measurement during over a ten-year period. Therefore, we concluded that the wet season rice production in Northern Thailand achieved efficiency, the technical progress and the productivity growth between 2009-2019 (Table 3).

\begin{tabular}{|c|c|c|c|c|}
\hline \multicolumn{2}{|l|}{ Table 3: Malmquist productivity index (MPI) summary of firm means. } \\
\hline Province & Efficiency change & Technological change & Total factor productivity change & Estimates of the productivity trend \\
\hline Chiang Rai & 1 & 1.006 & 1.007 & increasing \\
\hline Phayao & 0.998 & 1.006 & 1.003 & increasing \\
\hline Lampang & 0.994 & 1.005 & 0.999 & decreasing \\
\hline Lamphun & 1.002 & 1.005 & 1.007 & increasing \\
\hline Chiang Mai & 0.996 & 1.005 & 1.001 & decreasing \\
\hline Mae Hong Son & 0.985 & 1.005 & 0.991 & decreasing \\
\hline Tak & 0.991 & 1.005 & 0.996 & increasing \\
\hline Kamphaeng Phet & 1.003 & 1.007 & 1.009 & decreasing \\
\hline Sukhothai & 0.991 & 1.003 & 0.994 & increasing \\
\hline Phrae & 0.995 & 1.005 & 1 & decreasing \\
\hline Nan & 0.992 & 1.005 & 0.997 & decreasing \\
\hline Uttaradit & 0.986 & 1.004 & 0.99 & increasing \\
\hline Phitsanulok & 1.001 & 1.006 & 1.007 & increasing \\
\hline Phichit & 1.006 & 1.006 & 1.013 & increasing \\
\hline Nakhon Sawan & 1.003 & 1.006 & 1.009 & increasing \\
\hline Uthai Thani & 1.013 & 1.007 & 1.005 & increasing \\
\hline Phetchabun & 1 & 1.005 & 1.003 & increasing \\
\hline Mean & 0.997 & 1.005 & & \\
\hline
\end{tabular}

\section{Conclusions}

The empirical results showed that the technical efficiency of wet season rice production in seventeen provinces of Northern
Thailand in the crop year 2009/2010 - 2018/2019 by using an application of DEA Malmquist Index. The TE score revealed the production still needs to be improved due to the TE score is not close 
to 1.000 . The empirical revealed that Phetchabun province had the most effective from the crop year 2009 to 2019 as compared with other wet season rice producing provinces. This suggests that the Phetchabun province is the best producing province for wet season rice production in Northern Thailand. Meanwhile, Tak province which had the worst efficiency score, revealed the least efficiency's score among all the producing provinces in Northern Thailand. Besides, the average TE score of wet season rice production in Northern Thailand was 0.891 in the crop year 2009 to 2019 which means that it could be achieved $89.1 \%$ by technical efficiency and could be extended the efficient score $11.9 \%$ by decreasing of each input. The empirical results suggested that it could be improved the production for increasing the efficiency performance of wet season rice production in Northern Thailand.

In term of the Total Factor Productivity (TFP) change, an average score performed a high efficiency (1.003) during the ten years. The scores with greater than 1.000 in eleven provinces (Chiang Rai, Phayao, Lamphun, Chiang Mai, Kamphaeng Phet, Phrae, Phitsanulok, Pichit, Nakhon Sawan, Uthai Thani, and Phetchabun) which implied an improvement in the efficiency as well as technology. On the other hand, the scores with less than 1.000 was found in six provinces (Lampang, Mae Hong Son, Tak, Sukhothai, Nan, and Uttaradit) which implied a need to improve performance and technology. Therefore, we concluded that the wet season rice production in Northern Thailand achieved the efficiency improvement, the technical progress and the productivity growth between 2009-2019. Moreover, this study can provide important and useful information for farmers, producers, researchers, policy makers, and government agencies to set the plans for using technology to improve efficiency.

\section{Acknowledgement}

The authors would like to thank Department of Tropical Agriculture and International Cooperation, National Pingtung University of Science and Technology for supporting. Additionally, we are grateful for data support from Office of Agricultural Economics, Thailand.

\section{References}

1. Shahbandeh M (2019) Principal Rice Exporting Countries Worldwide $2018 / 2019$.
2. (2017) Thailand: Rice Production Rebounds Following El Nio-Commodity Intelligence Report USDA. United State of Department of Agriculture (USDA).

3. Kupkanchanakul T (2000) Bridging the Rice Yield Gap in Asia-Pacific Region. FAO Regional Office for Asia and the Pacific Bangkok Thailand 146-156.

4. (2017) International Production Assessment Division (IPAD). Office of Global Analysis (OGA).

5. Chiang Rai Times (2019) (CNT news) Rice Farmers in North, Northeast Thailand Face Worst Drought in 40 Years.

6. Chaovanapoonphol K, Battese G E, Chan (Christie) H S (2009) In: Lee J D, Heshmati A (Ed.) Productivity Efficiency Economic Growth in the Asia-Pacific Region. Physica-Verlag, Heidelberg, Germany 279-295.

7. Isvilanonda S (2017) Rice Policy in Thailand. Production and Economic Issue Kasetsart University Thailand.

8. Wongchai A, Ngamsomsuke K (2015) Efficiency Measurement on Rice Production in Thailand. The $4^{\text {th }}$ International Conference on Agricultural Economics, Prince of Songkla University, Thailand.

9. Charnes A, Cooper W, Rhodes E (1978) Measuring Efficiency of Decision Making Units. European Journal of Operational Research 2(6): 429-444.

10. Coelli T J, Rao D S P, Battese G E (1998) Chapter 6 Data Envelopment Analysis. In: Coelli T (Eds.), An Introduction to Efficiency and Productivity Analysis. ( $2^{\text {nd }}$ Edn), Springer Science and Business Media, Inc. Kluwer, Massachusetts, USA, pp. 161-181.

11. Malmquist $S$ (1953) Index Numbers and Indifference Curves. Trabajos de Estatistica 4(2): 209-242.

12. Fare R, Grosskopf S, Lindgren B, Ross P (1992) Productivity Changes in Swedish Pharmacies 1980-1989. The Journal of Productivity Analysis 3(1): 85-101.

13. Farrell M. J (1957) The Measurement of Productive Efficiency. Journal of the Royal Statistical Society (120): 253-290.

14. Caves D W Christensen L R, Diewert W E (1982) The Economic Theory of Index Numbers and the Measurement of Input, Output and Productivity. Econometrica 50(6): 1414-1939.

15. Fare R, Grosskopf S, Norris M, Zhang Z (1994) Productivity Growth, Technical Progress, and Efficiency

Change in Industrialized Countries. The American Economic Review 84(1): 66-83.

16. (2019) Agricultural statistics of Thailand in 2018/2019, Ministry of Agriculture and Cooperative, Office of Agricultural Economics, Bangkok, Thailand. Office of Agricultural Economics (OAE).

17. Coelli T J (1996) A Guide to DEAP Version 2.1 In: CEPA Working Paper (96/08), A data envelopment analysis (computer) program, Centre for efficiency and productivity analysis. Australia, pp. 27. 